\section{CONCLUSIONS.}

(1) Centrifugal cream is probably less desirable for infant feeding than gravity crean. As obtained from dealers it is often far from accurate in percentage.

(2) Siphonage for obtaining gravity cream is an accurate method, but one requiring considerable skill to perform accurately and safely.

(3) Dipping off the top milk is an accurate and safe method if reasonable care is used.

(4) The method for obtaining gravity cream by pouring off the top is very accurate and extremely simple. 'There is no instrument to be bought and kept clean. By this method it is possible to obtain eream of any clesired percentage up to $26 \%$.

(5) 'To ensure perfect accuracy, frequent examinations with the Babcock machine are required; but for practical purposes this is not necessary, provided the mixed milk from a well-regulated dairy is obtained.

\section{VARIATION IN THE COMPOSITION OF HUMAN MIIK.'}

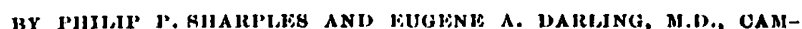
BIRIDGL, MABs.

ANAIYses of human milk liave been numerous, but few attempts have been made to carry out a series of analyses in a systematic manner. The purpose of the present investigation was to provide clata from samples numerous enough to sink the effect of any individual sample in the average of all the samples.

Collection of samples. - The samples were collected under as uniform conditions as possible. After the child had suckled in the morniug nursing for a few minutes, a sample of about $1 \mathrm{oz}$. was drawn by the breast pump. The sample was forwarded to the laboratory in a mailing case. 'The analytical work for all except a few of the samples was begun within a few hours of the collection of the samples. Some, however, were preserved until the succeeding day witls a drop of formalin.

The methods of analysis used were as follows :

T'otal solids. - The total solids were obtained by evaporation to constant weight on a water bath. Usually 2 grams were taken.

Fat. - 'The fat was determined by the Babcock method. In case the full $17.6 \mathrm{cc}$. were not available 10 cc. were taken, and the results calculated, to the normal.

Solids not fat.- The solids not fat were obtained by taking the difference between the total solicls and the fat.

Proteids. - A slight mochification of Ritthausen's method was used in the determination of the proteids. Five cubic centimeters of milk were diluted to 100 cc. and 2 cc. of copper solution ( $3 \mathrm{gm}$. copper sulphate to 1 liter) were added. A $6 \%$ caustic soda solution was run in until the solution was barely acid to phenol-phtalein. After the precipitate had subsided the solution was filtered through balanced filters, and the precipitate collected and washed on the filter. After drying at $150^{\circ} \mathrm{C}$. the filter was extracted with $76^{\circ}$ naphtha, and then the naphtha

\footnotetext{
1 Read at the Boston Medical Library Meeting, Feb. 23, 1003.
}

displaced with ether. The precipitate was dried again at $100^{\circ} \mathrm{C}$. and weighed. This last weight minus the weight of the ash of the precipitate gives the proteids.

Ash. - The ash was determined by igniting the total solids until white over a Bunsen burner.

Sugar. - I'he sugar was determined by difference. In a few samples as a check it was determined directly from the filtrate of the proteids with Fehling's solution.

Errors of analysis. - The different methods of analysis were chosen not so much to get absolute accuracy as to get strictly comparable results. The solids are capable of duplication within $.02 \%$, the fat within .10\%, the proteids $.05 \%$, the ash $.01 \%$, while the sugar when determined by difference would be subject to an error which is the algebraic sum of all the other errors. It is not likely to exceed .10\%. I3eside these general errors, individual samples were subject to the doubling of the stated error by the employment of half the usual quantity for analysis, and to aceidental errors such as the souring of the sample.

Results of analysis. - A scanning of the indi-

TA BLI I.

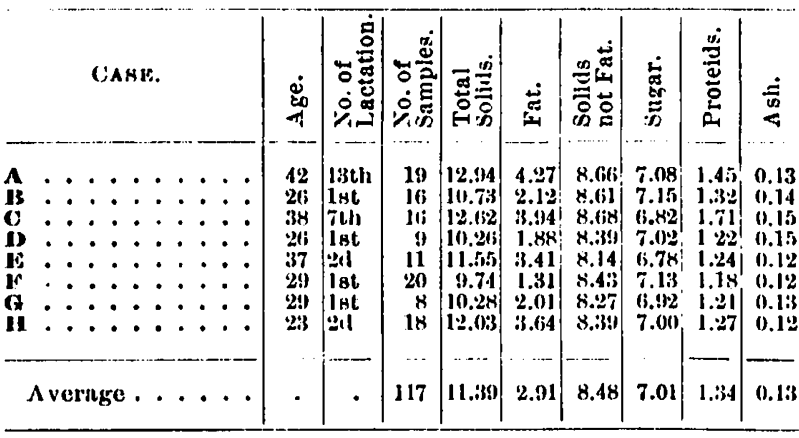

vidual analyses shows a wide variation in each and every constitutent, but especially in the fat. 'The fat varies from $.70 \%$ to $7.04 \%$, and even the samples from the same subject show almost as much variation. Cases $A$ and $k$, showing a very irregular and a very even milk, illustrate this point. In $\mathbf{A}$ the total solids vary much from week to week, but the graphic representation shows at a glance that the rariation is due to the fat and not to the other coustituents. Such a variation can hardly hold for the average of all the milk supplied at a nursing, and must to a considerable extent be clue to differences in the conditions of taking the sample. It is well known in the case of milch cows that the fat increases throughout the milking, and that the strippings are the richest. It is equally true of human milk. 'The average of Cases $A$ and $F$ further show how little can be deduced from even a series of analyses from one subject. In Case $A$ the fat is almost four times as much, the proteids $.3 \%$ more, while the sugar is $.05 \%$ less. These individual differences are only to be eliminated by averaging a large number of samples from many individuals.

Tables showing the averages for each week from the beginning of lactation still show the effect of the individual sample to a marked degree. Here again the variations are mainly in the fat. The solids not fat show a fuirly even line. A table 
Case A. Age 43.

TABLE II.

13th Lactation.

Week of Lactation.

I.Total Solids

II. Solids not Fat.

III. Fat

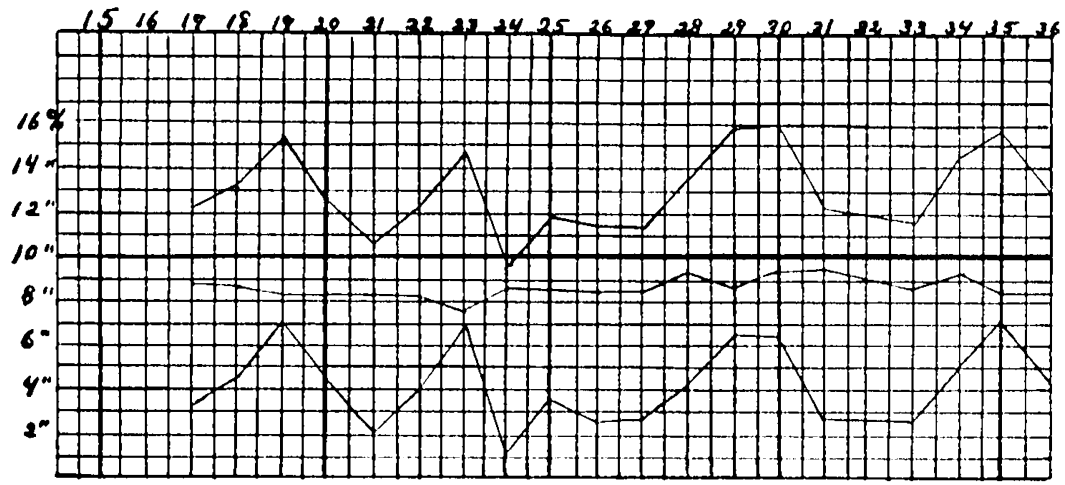

TABIEE III

Case F. Age 28. 1st Lactation. Week of Lactation

\section{I.Total Solids II. Solids not Fat}

III. Fat.

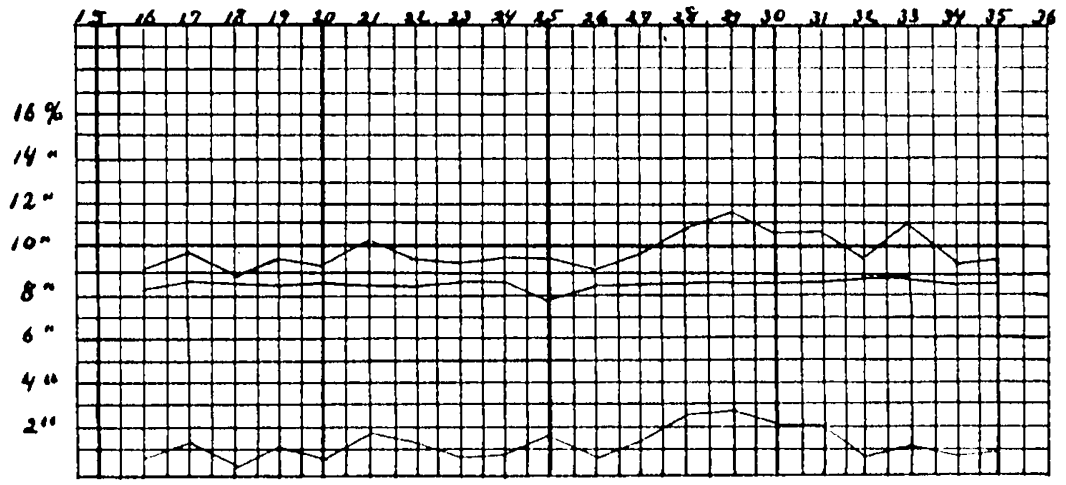

TABLE IV.

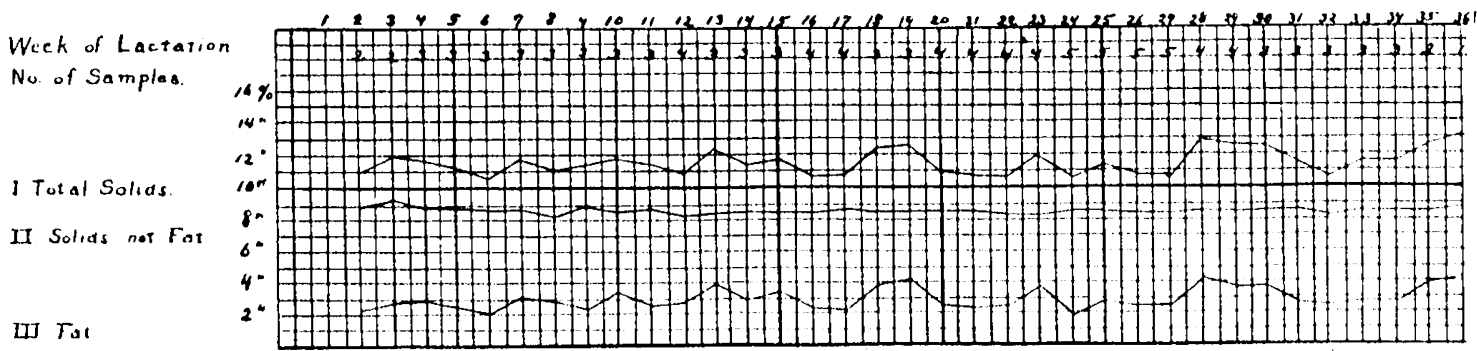

Variation in Composition in Weckly Periods calculated for periods of four weeks is, however, much more satisfactory. No period is represented by fewer than seven samples, and the number may run as high as nineteen. 'The straightening of the curve in the graphic table is very marked, and it is hard to escape the conclusion that if the number of samples were large enough the line would still further approach the general average of all the samples. 'The first two periods must, however, be excepted. In these the proteids are seen to decrease from 1.58 to 1.42 and 1.35 .
'TABLE V.

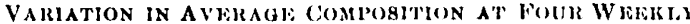
Plinions.

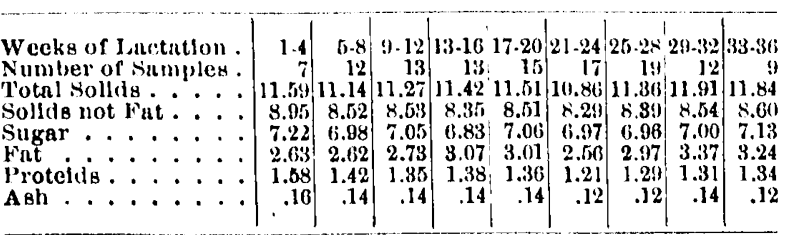




\title{
TABLE VI.
}

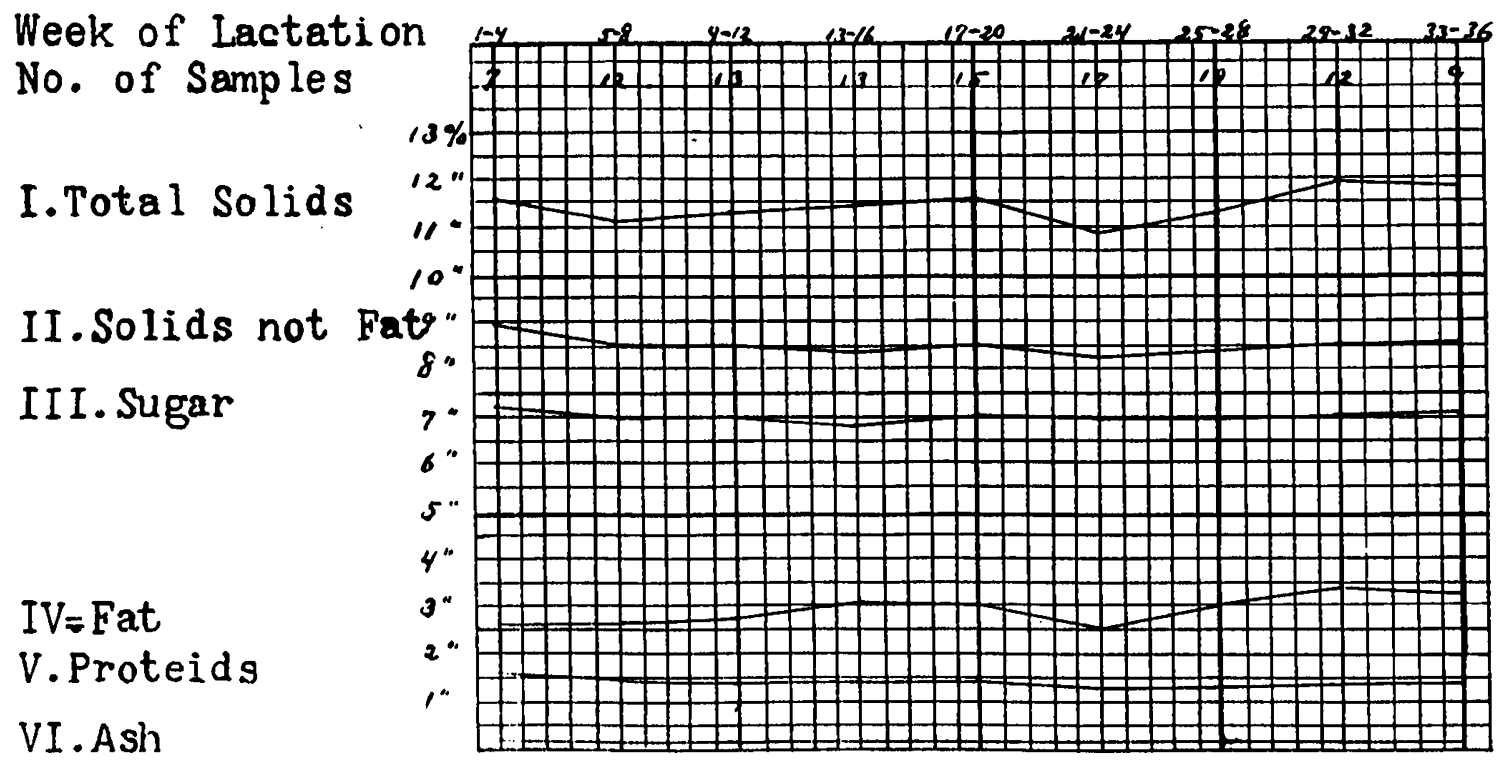

Variation In average composition at four-weokly periods.

A comparison of the results tabulated by the well, but the highest averages again are in the number of the lactations shows some marked differ- seventh and fifteenth lactations. The general averences. All the samples from cases of the first age of the proteids is .20\% more, and of the sugar is

T.A I3LIS VII.

VARIATION IN COMPOAITION BY NuMBEL OF JACTATION. First Lactation.

\begin{tabular}{|c|c|c|c|c|c|c|c|c|c|}
\hline CASF. & $\underset{4}{4}$ & 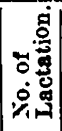 & 岁兽 & 驾总总 & 岕 & 兽蓠 & 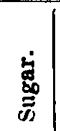 & 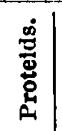 & ه্] \\
\hline 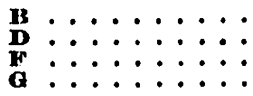 & $\begin{array}{l}26 \\
26 \\
29 \\
29\end{array}$ & $\begin{array}{l}\text { 1st } \\
1 \text { st } \\
1 \text { st } \\
\text { lst }\end{array}$ & $\begin{array}{r}16 \\
0 \\
20 \\
\gamma\end{array}$ & $\begin{array}{r}10.73 \\
10.26 \\
9.74 \\
10.28\end{array}$ & $\begin{array}{l}2.12 \\
1.88 \\
1.31 \\
2.01\end{array}$ & $\begin{array}{l}8.31 \\
8.39 \\
8.43 \\
8.28\end{array}$ & $\begin{array}{l}7.15 \\
7.02 \\
7.13 \\
6.132\end{array}$ & $\begin{array}{l}1.82 \\
1.22 \\
1.18 \\
1.21\end{array}$ & $\begin{array}{l}0.14 \\
0.15 \\
0.12 \\
0.13\end{array}$ \\
\hline Avera & • & . & 68 & 10.21 & 1.76 & $8.46 \mid$ & 7.09 & 1.28 & 0.13 \\
\hline
\end{tabular}

TA BLE VIII.

More than One Lactation.

\begin{tabular}{|c|c|c|c|c|c|c|c|c|c|}
\hline Cank. & क्ष & 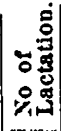 & 它总 & 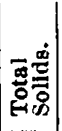 & 䓵 & 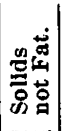 & $\begin{array}{l}\dot{8} \\
\dot{8} \\
\dot{\sigma}\end{array}$ & 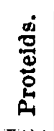 & 迺 \\
\hline 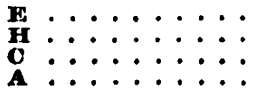 & $\begin{array}{l}37 \\
23 \\
38 \\
42\end{array}$ & $\begin{array}{r}21 \\
21 \\
7 \mathrm{td} \\
13 \mathrm{th}\end{array}$ & $\begin{array}{l}11 \\
18 \\
16 \\
19\end{array}$ & $\begin{array}{l}11.05 \\
12.03 \\
12.62 \\
12.94\end{array}$ & $\begin{array}{l}3.41 \\
3.64 \\
3.94 \\
4.27\end{array}$ & $\begin{array}{l}8.14 \\
8.39 \\
8.63 \\
8.66\end{array}$ & $\begin{array}{l}6.78 \\
7.00 \\
6.89 \\
708\end{array}$ & $\begin{array}{l}1.24 \\
1.27 \\
1.71 \\
1.45\end{array}$ & $\begin{array}{l}0.12 \\
0.12 \\
0.16 \\
0.13\end{array}$ \\
\hline Average . . . . & • & . & 64 & 12.37 & 3.87 & 8.50 & 6.94 & 1.43 & 0.13 \\
\hline
\end{tabular}

actation are grouped in Table VII, while the cases of two or more lactations are grouped in Table VIII. The fat in the first lactation averages $1.76 \%$, while it is $3.87 \%$, or more than double, in the other group. From the individual averages it is seen that the highest fat occurs in Case A, the fifteenth lactation; the next highest in Case $\mathrm{C}$, the seventh lactation; while the other two members of this group, $E$ and $H$, are both higher than the highest of the first group. The proteids do not fall in line so $.15 \%$ less in the second group. 'These variations are in accord with the variations which occur in the milk of a single individual, that is, a higher fat percentage is usually with a bigh proteid and a low sugar.

Conclusions.-(1) The avernge composition of human milk, as shown by 117 analyses, is :

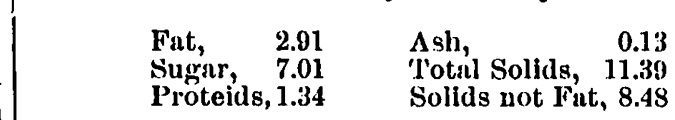

(2) There are wide variations from the average in milk from the same individual at different times.

(3) 'There are marked variations in the average composition of milk from different individuals.

(4) 'The average composition of human milk does not vary to any marked extent at different periods of lactation.

(5) During the first lactation the milk, on the average, is weaker in fat and proteids, but stronger in sugar than in subsequent lactations. These differences may or may not be due to age.

\section{Elinical g্Department.}

\section{'IRIKRESOI, IN PARA-URE'THRAI, ABSCESS.*}

\author{
BX M. L. HBIDINGSFELD, PH.1B., M.D., CINCINNA'TI.
}

Profcssor of Dermatology, Laura Memorial College; ('linical Lec. tiver on Dermatoloyy und Venercal Diseases, Miami Afedical Col. lege; Dermatologtse to I'resiyteriin Hospitai.

ONE of the most troublesome of the long list of vexatious and perplexing diseases which at times impose themselves on the practitioner of medicine is that occasioned from chronic gonorrhea or gleet, which, in spite of the most careful, well-regulated and painstaking treatment, pursues an exceedingly * Read before the North Kentucky Medlcal Soclety, Nov. 13, 1902. 